\title{
The Goodness of Means: Instrumental and Relational Values, Causation, and Environmental Policies
}

\author{
Patrik Baard ${ }^{1}$ iD \\ Accepted: 18 February 2019 / Published online: 28 February 2019 \\ (C) The Author(s) 2019
}

\begin{abstract}
Instrumental values are often considered to be inferior to intrinsic values. One reason for this is that instrumental values are extrinsic and rely on two factors: (a) a means-end relationship that is (b) conducive to something of final or intrinsic value. In this paper, I will investigate the conditions under which bearers of instrumental value are given different value or owed different levels of respect. Such conditions include the number of means that are conducive to something of final or intrinsic value as well as the form of causality that is implied. It will be suggested that different numbers and causal relations will imply different degrees of reverence or respect to the bearers of instrumental value. I will also critically investigate recent proposals such as relational values that allegedly go beyond the distinction between instrumental and intrinsic value. Drawing from this critical analysis, a nuanced picture of instrumental value will be provided.
\end{abstract}

Keywords Instrumental value $\cdot$ Species $\cdot$ Intrinsic value $\cdot$ Relational value

\section{Introduction}

Intrinsic value often takes center stage in ethical reasoning and provides a central pillar for reasoning about how we should live and act. In contrast, claiming that something has instrumental value is taken to imply that it is inferior and pedestrian, as it does not have value on its own merit but only in relation to extrinsic factors, primarily a causal relation to something having intrinsic or final value. Despite being seemingly straightforward, the concept of instrumental value raises several questions. Commonly, an entity is instrumentally valuable if it is successfully conducive to something of intrinsic or final value, as instrumental value is contingent on standing in a causal relation to something of intrinsic or final value. But the causal influence raises further issues for assessing instrumental value. What if there are

Patrik Baard

Patrik.baard@slu.se

1 Swedish Biodiversity Centre, Box 7016, 75007 Uppsala, Sweden 
several equally successful means to something of intrinsic value-would they then have the same value and be substitutable? Or what about instances when there is a long chain of actions required, all of them necessary but neither is sufficient. What if there is only one mean conducive to something of intrinsic value-would that not merit great reverence to the bearer of instrumental value, perhaps regarding it as having equal value as that which it is conducive to? Put differently, what conditions influence the extent of instrumental value? It does not seem reasonable to grant a bearer of instrumental value the same value as the intrinsic or final value that it is conducive to. Still, it seems strange to propose that a bearer of instrumental value is regarded as substitutable or not meriting respect solely due to its instrumental value. While it is already known that there are possible ways of considering that entities having instrumental value are worthy of indirect respect-Kant's discussion of indirect duties for instance - an analysis and specification of the conditions that regulate the respect owed to entities having instrumental value has not been proposed.

The aim of this paper is to analyze what the relevant conditions are when determining instrumental value. Instrumental value is contingent upon a causal relation to intrinsic value, but how does it matter axiologically whether a means is a necessary or sufficient condition, or whether there are several, very few, or only one means conducive to intrinsic value? The purpose is to highlight a category of value that is rarely given attention per se. Moreover, the analysis is also motivated by recent discussions on going beyond intrinsic and instrumental values, such as relational values. It has been suggested that relational values provide a way out of the binary distinction in environmental policies (Chan et al. 2016). However, the distinction between instrumental and intrinsic value is still often raised in discussions on conservation ethics and ecosystem services (see for instance Sandler 2012a), including expert organizations such as the Intergovernmental Science-Policy Platform on Biodiversity and Ecosystem Services (IPBES 2018). A greater explication of what is meant by referring to instrumental values is therefore useful to see what it is suggested one goes beyond, and furthermore whether instrumental values can accommodate relational values. The implications of the current investigation of instrumental values for relational values will be discussed in Section "Instrumental values relative to relational values".

The paper will first recount some differences between instrumental and intrinsic value. Then, a discussion will follow on the relevance of means, partially understood as causes, and how they can be valued differently depending on different conditions. Finally, conservation ethics and management will be used as examples in the discussion, by focusing on how we should understand keystone and umbrella species and their relation to valuable ecosystems.

\section{Instrumental and Intrinsic or Final Value}

To Moore (2004: 27), the question of what things are good in themselves is the primary ethical question. W. D. Ross made similar observations (Ross 2002: 91). In environmental ethics, intrinsic value has traditionally been central for setting the boundaries of our interaction with the environment, although the role of intrinsic 
values has also been criticized (O'Neill 1992). It has also been suggested that there are different kinds of intrinsic values (O'Neill 1992; Sandler 2012b). On the one hand, intrinsic value is defined negatively as that which has non-instrumental value; on the other hand, the concept intrinsic value refers to "the value an object has solely in virtue of its intrinsic properties" (O’Neill 1992).

But what about instrumental values? For the most part, instrumental value implies some form of relation to that which has intrinsic or final value. But, how is intrinsic value related to instrumental value? Minimal definitions of instrumental value may read as follows:

i. "Objects, activities, or whatever, have an instrumental value if they are valued for the sake of something else" (Korsgaard 1983: 170).

ii. "An object has instrumental value insofar as it is a means to some other end" (O’Neill 1992: 131).

These definitions fail to specify the relation between the bearer of instrumental value and the "something else" by virtue of which it is valued, but usually it is implied that there must be something that has intrinsic or final value, or we would end up in infinite regress (O'Neill 1992: 131). Some definitions specify the end that the bearer of instrumental value is conducive to, and its value derivative of:

iii. "To attribute instrumental goodness to some thing is primarily to say of this thing that it serves its purpose well" (von Wright 1963).

iv. 'Whenever we judge that a thing is 'good as a means,' we are making a judgment with regard to its causal relations: we judge both that it will have a particular kind of effect, and that that effect will be good in itself" (Moore 2004: 22).

v. "Many objects are valued merely as means to other objects- they are valuable solely by virtue of the fact that they will produce (or help produce) those other objects. Those things valued as a means in this way possess 'instrumental' value. [...] But eventually — or so the thought goes — we must reach objects that are valuable as 'ends' or 'for their own sake'" (Kagan 1998: 278-279).

vi. "Instrumental value is the value that something - an entity, act, or state of affairs - has as a means to an end [...] That something is an effective means to some end does not itself result in it having instrumental value. The end must also be that of some entity or be valuable or worthwhile. Thus, instrumental value is always derivative on the final (non-instrumental) value of something else. It is also always conditional" (Sandler 2012b: 16-17).

Rønnow-Rasmussen (2002) has proposed two different senses in which the notion of "instrumental values" is used, strong and weak:

vii. "Strong: ' $x$ has instrumental value' means ' $x$ bears a (certain particular) value, and it bears this value only if $x$ is conducive to (the existence of something that has) a final value." 
viii. "Weak: ' $x$ has instrumental value' means ' $x$ is conducive to (the existence of something that has) a final value"” (Rønnow-Rasmussen 2002: 25).

Thus, to be a means to something that has intrinsic value is a necessary condition for having instrumental value, at least according to definitions iv and vi, but definition ii similarly implies some form of causal relation between that having instrumental value and that having intrinsic value. This limitation omits several causes from having instrumental value, as it is exclusively those that lead to something that has final or intrinsic value that are regarded as having instrumental value. Other causes are merely instrumental. They may bring something about, but if this something does not have intrinsic value, they fail to have instrumental value.

Does the requirement of a causal relation imply that instrumental values are agent-neutral? As noted by von Wright (1963), instrumental goodness is derivative of a purpose. The instrumental goodness of a knife is contingent upon the purpose of the knife, that is, in cutting slices. The applicability of the phrase "this is a good knife" will differ depending on whether the purpose is to cut papers in a book or to cut a steak. However, when comparing knives an agent can be mistaken regarding the smoothness of the cuts, thus implying that one knife makes smoother cuts than another. Von Wright concludes his discussion on instrumental goodness by stating, "genuine judgments of instrumental goodness are always objectively true or false" (von Wright 1963). However, as Moore observes, "to find causal judgments that are universally true is notoriously a matter of extreme difficulty" (2004: 22). Despite such difficulties, it is reasonable that one's judgment regarding the instrumental goodness of a thing can be true or false. Korsgaard draws on Kant to present an alternative view regarding the objectivity of determining the goodness of means when she writes, "it is not because of the ontological property of being productive of an intrinsically good end that means are good but rather because of the law of practical reason that "whoever wills the end, so far as reason has decisive influence on his action, will also the indispensably necessary means to it that lie in his power', (Korsgaard 1983: 183; quote from Kant 1998: 28). However, even if the choice of ends in Kant's view is dependent on the good will, the choice of "indispensably necessary means" would rather suggest that Kant is talking about means that are objectively required for the chosen end. Whether the choice of ends is agent-neutral or not is partly a meta-ethical issue. But it would seem as if instrumental values are agent-neutral to the extent that they imply some form of means-end relation, implying causality.

However, causality is an insufficient condition of instrumental values. ${ }^{1}$ This is consistent with Rønnow-Rasmussen's distinction between strong and weak instrumental values, where weak instrumental value requires conduciveness, but, as he writes, "there is no reason why 'being valuable' somehow would logically follow

\footnotetext{
1 In some cases, causal properties may (in part) provide the foundation for intrinsic value (Kagan 1998). It is, for instance, not unreasonable to say that the usefulness of a skill provides part of the intrinsic value of that skill (Kagan 1998: 285). Similarly, the pen that Lincoln used to sign the Declaration of Emancipation has intrinsic value by virtue of it having been used for that purpose (Kagan 1998: 285).
} 
from the meaning of 'being conducive to value"” (Rønnow-Rasmussen 2002: 25). That is, the mere fact that $\varphi$ is conducive to $\psi$ does not make $\varphi$ valuable. For instance, Moore's description of "good as means" is the weak form of instrumental value (Rønnow-Rasmussen 2002: 28). Consequently, the identified means is not a bearer of value at all (Rønnow-Rasmussen 2002: 25).

Instrumental value derives from an entity's conduciveness to final value. Thus, the value is extrinsic. But, extrinsic value is not always instrumental (Korsgaard 1983: 171). Zimmerman suggests that it may be customary to talk as if the value of $\varphi$ is derivative of $\psi$ when it comes to the relation between non-final or extrinsic and final value (thus, in what follows, he is not talking about instrumental but rather extrinsic value): "it would be better to think of the former not as being derivative from the latter, but as being reflective or revelatory of the latter: (Zimmerman 2001: 44). Extrinsic value is different from instrumental value (Korsgaard, 1983), as extrinsic value does not require a causal relation in the sense of bringing something about. A thing, such as Lady Diana's wedding dress, may derive its value from the fact that it belonged to Lady Diana (Rabinowicz and Rønnow-Rasmussen 2000; Peterson and Sandin 2013; Rønnow-Rasmussen 2002: 35). However, the dress is not instrumental in a causal sense but is rather derivative.

What characterizes the specific relation between something of instrumental value, $\varphi$, and something of intrinsic value, $\psi$, where $\varphi$ is a means that can bring about $\psi ? \psi$ is then the source of value for $\varphi$, or the value of $\varphi$ is derivative of the value of $\psi$. The value of $\varphi$, having instrumental value, is extrinsic in the sense of being derived from (a) $\varphi$ 's causal relation, or conduciveness, to $\psi$, and (b) $\psi$ 's intrinsic or final value. This excludes that which is merely instrumental. Causality is a necessary though not sufficient condition for something having instrumental value. However, there are different forms of causes, which influence how we value a bearer of instrumental value.

\section{Valuing Means}

Rønnow-Rasmussen (2002: 25) includes a conjunction for the strong sense of instrumental value (see definition vii), where a bearer of instrumental value is valuable, and this value is contingent upon the bearer being conducive to a final value. Furthermore, due to this conjunction, it is only in the strong sense that a bearer of instrumental value has value, as it does not follow that a thing is valuable only because it is conducive to value.

Being conducive to-or a means to-implies a causal relationship of that which has instrumental value to that which has intrinsic or final value. It enables the bringing about of something or makes that bringing about more likely. But, how are we to understand this cause, and how do we determine whether the value of or care for something is conducive to something of final or intrinsic value? Is the value of the bearer of instrumental value equivalent to that which it is conducive to, or is it a reduced value? Do we always have to care less for a bearer of instrumental value than for the intrinsic value as such? 
This section investigates this issue and discusses necessary and sufficient causes as well as the substitutability and distribution of instrumental value. What is of interest is whether different causes will merit different forms of respect and care.

\section{On the Quantity of Means}

Suppose that there is something that is intrinsically valuable but that can only be achieved through a single mean. Contrast this with something intrinsically valuable that can be achieved through several means. Will factors such as quantity make a difference regarding treatment? They may make a difference, as the following three cases aim to illustrate.

Parsimony: If there is only one mean to $\psi$, we can surmise that in $\varphi$ to $\psi, \varphi$ reflects $\psi$. That is, $\varphi$ has the same value, importance, or weight as $\psi$, assuming that this is the sole manner of bringing $\psi$ about. Say that we have a natural area with sublime beauty, and this is the only such area in the world that enables such an experience. We then have great reason to care for that nature area. However, even if it enables experiencing sublime beauty, the area is not sublime beauty itself, and it is therefore not equivalent with sublime beauty, even if it reveals or reflects it and is the sole manner of doing so.

Temperance: Assume that there are several elements that will lead to an intrinsic value, such as knowledge. Ross suggests three elements characterizing a state of knowledge, each being sufficient but none being necessary: (i) the degree of its groundedness on fact, (ii) the degree to which the strength of conviction with which it is held corresponds to its groundedness, and (iii) the generality of the fact known (Ross 2002: 148). If an agent cannot do $\varphi_{\mathrm{i}}$ but can still do $\varphi_{\mathrm{ii}}$, then that agent can still reach the end of acquiring knowledge, and knowledge have intrinsic value. As long as there is an option with an equal or approximate result, that which is omitted can be substituted. If $\varphi_{\text {iii }}$ is not an option, we can most likely expect the actions of the agent to be cautious in order to avoid foregoing the opportunity of either $\varphi_{\mathrm{i}}$ or $\varphi_{\mathrm{ii}}$.

Gluttony: What if there is an intrinsic value, pleasure (that is, a world in which hedonist utilitarianism is true), which can be fulfilled through innumerous means? Now we may be a little concerned about whether we are still talking about the same thing as in the previous cases. An agent living in such a universe can substitute any of the entities that provide pleasure with any of the other innumerous entities that lead to the same amount of pleasure. Agents in such a universe would hardly have to consider cautiousness in their dealings with their surroundings.

Surely, an intuition that the number of means is important seem reasonable, in part, to whether we understand bearers of instrumental value as reflecting or being derivative of the intrinsic value of that which they aspire to fulfill. However, the notion of causality, being a component of means, lurks in the background. The next section will bring it out. 
Table 1 Necessary conditions as if-then clause

1.

If $\psi$ occurs, then $\varphi$ will have occurred

\section{Means Understood as Causes}

In Gluttony, there was absolute substitutability, whereas in Parsimony, there was no substitutability. We can see that in each case, $\varphi$ is conducive to something that has intrinsic value. The difference between Gluttony and Parsimony is one of causation, more specifically about necessary and sufficient conditions for something to occur. What follows will focus primarily on whether a specific cause actually gives rise to a specific outcome.

There are numerous challenges to certainty regarding causal relations in practice. Some are empirical, such as whether we can generate evidence that points in a specific direction regarding the relation between two elements of cause and effect. Other challenges are epistemological and relate to our understanding of causality. Aristotle distinguished between four causes (Falcon 2015): material cause, formal cause, efficient cause, and final cause. Thus, for example, bronze is a material cause for a bronze statue, whereas the form of the bronze statue is the formal cause. The artisan is the efficient cause, which sets things in motion, and the final cause is the purpose of the statue (Falcon 2015). Hume famously provided central challenges to the idea of causality, which were taken up by Kant and continue to this day.

This is not the place for dealing with the great challenges posed by Hume; rather, we will take a more practical turn. One way to generate greater understanding of the role causality has in means may be to consider necessary and sufficient conditions (Mackie 1965). Mackie (1965) proposed that a cause fulfills at least INUS conditions, that is, that a cause is an "insufficient but necessary part of a condition which is itself unnecessary but sufficient for the result." One may thus replace "cause" with "INUS condition." However, even if that is often what is meant when we use the concept "cause," in the following only necessary and sufficient conditions will be used, respectively, for the sake of analysis.

If something is a necessary but not sufficient cause for an outcome, it must always be part of the cause that brings this something else about. Thus, if the intended outcome occurs, it will always have been preceded by (at least) the necessary cause. If something is a sufficient but not necessary cause for an outcome, it means that the occurrence of the cause will always lead to the outcome, but the outcome may come about in other ways.

For now, we can illustrate necessary causes, stipulated as an if-then clause (assuming that it is possible to identify such causes in isolation) (Table 1).

If $\psi$ (a virtue, a duty, utility, or protection of organisms carrying intrinsic value) occurs, then $\varphi$ will have occurred prior to it (a virtuous action, an action according to duty, an action resulting in the greatest utility, or protection of endangered species). Point 1 is similar to Parsimony. It should be noted that even if $\psi$ is always preceded by $\varphi$, the occurrence of $\varphi$ does not have to lead to $\psi$. Therefore, we cannot deduce that if $\varphi$ occurs, then $\psi$ will occur (see Point 3 below). 
Table 2 Conjunction of necessary conditions as if-then clause

Table 3 Disjunction of sufficient causes as if-then clause

3.

If $\varphi 1$ or $\varphi 2 \ldots$ or $\varphi$ occurs, then $\psi$ will occur

There can be, and often are, sets of causes that are necessary for $\psi$ to occur, as illustrated by the following conjunction (Table 2 ).

There are several different though contiguous ways of understanding such sets. One is that an agent may have to perform several different actions in order to make $\psi$ come about. Another is that an agent may ask itself why it wants a particular thing, such as to buy a new car. The agent may sense that a new car leads to greater mobility and travel, and greater mobility and travel lead to a sense of freedom. However, a sense of freedom is, for this agent, a good without reference to anything it leads to. If we did not permit such a set of actions to count as a cause, we would have to acknowledge that it is only the temporally most proximate $\varphi$ that has instrumental value, as it is that which leads to that which has intrinsic value, which seems to be a problematic case.

An additional way of understanding such sets of causes is the notion of "organic unities," where no particular entity in a whole has intrinsic value but combined the elements do (Moore 2004: 27ff). To some, such as Robert Nozick (1989: 164), intrinsic value is exclusively applicable to organic unities. The value of an organic unity is contingent upon two factors: diversity and the degree of unity (Nozick 1989: 164). These two factors may often work at cross-purposes since the greater the diversity, the more difficult it may be to bring an entity containing multiple parts into unity. However, Nozick (1989: 165) states that this notion of intrinsic value as equivalent to organic unity may explain why we hold valuable, for instance, "whole ecological systems with their complexly interrelated equilibria." Even so, in ecological systems, the assessment of unity and diversity is likely to be somewhat controversial (MacLaurin and Sterelny 2008; Woods 2017).

Contrasted to necessary causes are sufficient ones. One can also illustrate sufficient causes through the if-then clause, only reversed and with disjunctions, ${ }^{2}$ if there are several sufficient means (Table 3).

Here, if $\psi$ occurs, we cannot deduce that any particular $\varphi$ has occurred. It may even be the case that no $\varphi$ has occurred, as none of them is necessary. However, the point is that there are several causes, which, should they occur, are all sufficient for producing the outcome $\psi$.

This instance can be compared with Temperance above. Say an agent wants to become knowledgeable, as knowledge has intrinsic value. However, due to the

\footnotetext{
${ }^{2}$ A single $\varphi$, or a conjunction of $\varphi$ 's, may also be sufficient conditions. It should be noted that a set of necessary causes cannot be disjunctive.
} 
Table 4 Valuation of necessary conditions as if-then clause
4

$(100)$
4. If $\psi$ occurs, then $\varphi$ will have occurred (100)
Table 5 Valuations of disjunction of sufficient conditions as if-then clauses

\begin{tabular}{lllll}
\hline 5. & If $\varphi 1$ or & $\varphi 2$ or & $\varphi 3$ occurs, then & $\psi$ occurs \\
& $(100)$ & $(100)$ & $(100)$ & $(100)$ \\
$5 *$ & $(33)$ & $(33)$ & $(33)$ & $(100)$ \\
\hline
\end{tabular}

nature of whatever topic of interest, one of the alternatives is closed to the agent. Ross (2002), for instance, suggested a distinction between metaphysics, with great generality but less groundedness in fact, and chemistry, with groundedness in fact but less generality. If one chooses to study something for which there is no availability of knowledge through the generality of known facts, then groundedness on fact remains, and vice versa. The main point is that there are still means to achieve that which has intrinsic value: knowledge. Point 3 is also similar to Gluttony but differs in terms of the quantity of means.

\section{Valuing Means}

What does the above imply for our reverence of means and the moral weight of instrumental causes? Surely, there must be some sense to the intuition that the form of causality matters to our treatment of that which has instrumental value. For instance, one is sometimes justified in treating a means to an intrinsic end with similar regard as the end itself, given that this particular end is only conducive to that specific means having occurred. That specific end is always preceded by a specific means and never occurs in the absence of that means. It may not only be said to derive its value from the intrinsic end but also that it may reflect that value. It seems as if they get the same status or worth as that which has intrinsic value. Thus, it is in a sense equivalent to that which has intrinsic value.

Say that we place a value on an entity that has intrinsic value in the following manner, solely for illustrative purposes (Table 4).

We should likely treat the necessary (and perhaps sole, if also sufficient) means to that which has intrinsic value with the same reverence as that which has intrinsic value in and of itself. The value is reflected in full and is equal since without it we cannot achieve that which has intrinsic value.

But, does the number make a difference, and if so, how? Let us again suppose that there are three sufficient but not necessary causes of $\psi$, such as in Temperance (Table 5). Are we justified in our judgment that they all reflect the same value as above?

This may be justified when we are discussing small numbers. But even so, it is awkward, as $\varphi_{1-3}$ are all substitutable, and furthermore, since they are not necessary, $\psi$ may be fulfilled by other means that are neither necessary nor sufficient 
Table 6 Valuations of sets of conjunctions of necessary conditions, including organic unities (6*), as ifthen clauses

\begin{tabular}{llll}
\hline 6. & If $\psi$ occurs, then & {$[\varphi 1$ and $\varphi 2$ and $\ldots$ and $\varphi \mathrm{n}]$} & will have occurred \\
$(100)$ & {$[?]$} & \\
$6 *$ & If $\psi$ occurs, then & {$[\varphi 1$ and $\varphi 2$ and $\ldots$ and $\varphi \mathrm{n}]$} & will have occurred \\
& (more than the sum of $\varphi n)$ & {$[?]$} & \\
\hline
\end{tabular}

unto themselves. Thus, if we lose one, it can be substituted for another. But, should we then divide the value between them and assume that they are, in a somewhat rigorous manner, treated with a third of the reverence and respect that befalls that which has intrinsic value (as in $5^{*}$ ). If one of them exits the scene, then the remainder are treated with slightly more respect, and so forth, until there is only one remaining, which is then the sole option and thus reflects the intrinsic value.

Recall the case of Gluttony, where there was great substitutability between different means of achieving a specific end, which was good as an end. It cannot possibly be the case that we have, for instance, a thousand means treated with equal value as that which has intrinsic value. This would stifle action in many occasions. However, it does not seem justified to treat each entity as having 1/1000 of that value either, as the high degree of substitutability permits substantially reckless behavior toward entities that have moral worth, even if they are derived from that which has intrinsic value.

Say that a chain of events is required to fulfill something that has intrinsic worth (as in 2 above). Neither of the elements is sufficient, but taken together, all of them are necessary, such as making great societal transitions in small steps to respect future generations or environmental collectives. The same reasoning applies to organic unities, but with a significant difference. If we accept that intrinsic value is equivalent to organic unity, then the value of each individual $\varphi$ in example 6 is not unknown; rather, the value of $\psi$ will increase along with the diversity and unity of $\varphi_{\mathrm{n}}$. The greater $n$, and the greater unity of $n$, the greater the intrinsic value, if Nozick is correct. Thus, the case of organic unities and value will be like $6^{*}$ (Table 6).

It would seem impossible to ascribe a specific value to each $\varphi$, but they should presumably all be treated with respect and reverence, for they are all conjointly required. But, how far would that suggestion extend? It may be an unreasonable number of actions, which must all be performed to achieve or protect $\psi$, with all of them being necessary for the set to provide a causal link to $\psi$. An alternative would be to ascribe the last $\varphi, \varphi_{n-1}$, the same value as $\psi$ since it is the last action in a chain of actions that make $\psi$ come about. But, we may ask, why the last $\varphi$, the (temporally) most proximate cause, and not any $\varphi$ ? Given that many decisionmaking instances are characterized by a lengthy chain of actions, this is quite problematic. It would be wrong to treat each $\operatorname{singular} \varphi$ with the same value as $\psi$, as neither is sufficient or, unto itself, necessary. However, it would be equally problematic to treat all instances of $\varphi$ as without value since they, agglomerated but never in isolation, make $\psi$ come about. 
This section has investigated the role that means (implying causality) play when determining instrumental value. It was stated that causal relations take many forms. First, there may be a difference in quantity regarding how many means are available to achieve a final end. Second, to broaden the analysis, necessary and sufficient causes were investigated the. Finally, the issue of how to value bearers of instrumental value was investigated, contingent upon the prior discussion on the quantity and kinds of causal relations that means entail. This has provided a more nuanced description of instrumental values than has previously been offered, as it has included causality, which is implied in a means-end relationship, being a condition for instrumental value.

\section{Environmental Policy, Relational Values, and Keystone and Umbrella Species}

Environmental ethics often rejects the notion that non-human organisms have solely instrumental value. If non-human organisms have solely instrumental value, they are substitutable, and we have no direct duties toward them. That being said, a bearer of intrinsic value may also have instrumental value. An ecosystem may be valuable in itself, for instance, but also be a means to the extent that it provides ecosystem services. However, the forms of values differ in kind, even if a single entity may have both intrinsic and instrumental value. The difference in kind is due to the fact that intrinsic value is, by definition, not contingent on extrinsic factors.

Moreover, in some cases, there is such great instrumental value that it will outweigh other values. This is seen, for example, in the case of ecosystems, which, according to Robin Attfield (2015), do not have intrinsic but rather instrumental value. Ecosystems are instrumental through "facilitating the existence of whole generations of creatures bearing intrinsic value, which could not exist without them" (Attfield 2015: 41). However, that instrumental value is so great "as to be capable of outweighing the value in the lives of even the individual human beings who could be brought into being and located there in their stead" (Attfield 2015: 41). Thus, even if having solely instrumental value, a bearer of such value can be preserved and seen to reflect the intrinsic value that it is conducive to, similar to Parsimony and Temperance above.

Even if one grants instrumental value to non-human organisms, one is not to treat such organisms with a lack of respect or moral worth. Rather, the point is to show that there are still good reasons, within a framework of instrumental values, to act with reverence and respect toward non-human organisms in their capacity as bearers of instrumental value. If this succeeds, one upside is that one can act with respect without the requirement to consider claims regarding intrinsic value that may seem to have problematic connotations for those not well versed in environmental ethics. Exactly what constitutes a bearer of intrinsic value need not concern us too greatly here.

Concepts such as keystone and umbrella species point toward necessary or sufficient conditions for the integrity and persistence of specific ecosystems, and the identification of such species has practical relevance for conservation policies. A 
keystone species is instrumental in upholding the structure of an ecological community (Noss 1990; MacLaurin and Sterelny 2008: 115), whereas an umbrella species is an endangered species that requires a large habitat. A keystone species is a necessary condition for upholding the structure of its particular habitat, as it increases the likelihood of the persistence of the habitat. That is, if a particular habitat that has specific characteristics comes about and continues to be, there is a high likelihood that a specific keystone species resides there. In contrast, an umbrella species is a sufficient condition for protecting the biodiversity of an area. If a specific umbrella species resides in a specific habitat, and if that species is endangered and protecting the habitat is required to protect the umbrella species, the habitat will be preserved. The umbrella species is not a necessary condition, as the habitat may be preserved by other means. But, does this make a difference in terms of the reverence and respect they should be paid as a means to achieving the objective of preserving habitats, ecosystems, many other species, and individual organisms?

Assume that the habitat in which a keystone species resides is considered to have intrinsic value and is making a claim on us to be preserved. As long as we maintain that there is no other cause that will give rise to the effect of preserving that habitat, we can be justified in treating the keystone species as a proxy for that which has intrinsic value. That is, it is then understood as having the same value as the habitat, and the duties to preserve the habitat are reflected in the necessary means to protect the keystone species. Protecting the habitat - and all its other organisms - is of equal importance to protecting the keystone species.

When it comes to umbrella species being a sufficient cause for preserving a habitat, we can assume that there are other causes that can provide the means to the same target of habitat preservation. We can, for instance, assume that even if that umbrella species becomes extinct or migrates, the habitat can still be preserved. This is so because the umbrella species is not a necessary cause for the habitat, as it can be preserved by other means. While some of those means may be known to us, it would seem that not all of them have a similar good. Consider, for instance, $\varphi_{1}$, conserving the umbrella species, or $\varphi_{2}$, setting up a fence to physically protect the habitat. $\varphi_{2}$ may permit the extinction of the umbrella species and thus provide less goodness than $\varphi_{1}$, at least intuitively, even if both achieve the same objective.

\section{Do instrumental Values Justify Substitutability?}

Do instrumental values necessarily justify substitutability? Not in the case of Parsimony, and to a lesser extent in Temperance than in Gluttony. Similarly, they do not in the case of keystone species, being a necessary condition for the persistence of ecosystems. Substitutability is sometimes discussed in "weak sustainability" (Beckerman 1994). Given that an aggregated level of value does not diminish, one is free to substitute the individual entities if natural and humanmade capital are substitutable (Birnbacher 2004; Beckerman 1994). This seems to be consistent with the discussion above on instrumental values. However, there are at least two caveats to substitutability: one concerns value while the other is related to uncertainty. A rights-based as opposed to a utilitarian framework may 
suggest that when we are discussing ecological systems, we are discussing the substitutability of entities, such as organisms, which may have rights or be worthy of respect. It would thus be a moral wrong to subsume their interests into the greater good. Furthermore, some would argue that even if we were allowed to replace entities, such as organisms, value would be lost (Katz 1985). The reason for this is that properties such as naturalness and wildness, where a lack of human-intended design is a central component (Woods 2017), would reduce the value of the substitute. However, the above discussion on the quantity of means accommodates such issues. To the extent that value is lost, the "means" by which, say, ecosystem integrity is upheld, would presumably be a reduced value rather than a substitute as the intrinsic value is not reflected in full.

However, substitutability may also be prohibited by way of instrumental values. One example is the well-known "rivet" argument (Ehrlich and Ehrlich 1981). If we imagine that planet Earth is an airplane and different species are rivets that enable us to fly (or enable ecosystem services), then it would be wise to ensure that all the rivets are properly maintained. This is because we do not know which rivet will be the one that makes the plane crash (or lead to the cessation of ecosystem services). The rivet argument attempts to address the uncertainty regarding the specific role that species play in ecosystems. Even so, it is an argument by analogy and thus includes all the weaknesses of such arguments (Sarkar 2005: 14). Furthermore, many rivets on an airplane can be lost without affecting the safety of the airplane (Sarkar 2005: 15). Similarly, many species may be lost without affecting the persistence of an ecological community. However, the argument still justifies the preservation of keystone species, which have a greater causal effect on such persistence (Sarkar 2005: 15).

One modest outcome is that one has an obligation to pay reverence to means that are instrumental to both specific ends and those that have intrinsic value, such as protecting and respecting ecosystems. Of course, in real-life cases, there will most likely be an abundance of causes, not all of which are sufficient or necessary. Such complexity will most likely add to the need to pay reverence to means, as the current available means may be the only known manner in which for instance an ecosystem can be maintained.

Furthermore, and perhaps most importantly, one cannot automatically say that all sufficient means will have the same value or be worthy of the same respect as that which they lead to. However, one can say that there is something morally blameworthy with the agent that treats them as having virtually no value. A moderation in substitutability is probably a good thing, as one does not know, for instance, how long remaining means will last (recall Temperance above). The uncertainty of both causal relations and the intrinsic values of non-human organisms may give rise to actions based on erroneous means/ends judgments as well as on erroneous judgments of intrinsic value. It may be the case that other species are keystone species or that an umbrella species is not only a sufficient condition among several others but also a sole and necessary means. Given the difficulties of understanding the complexities of ecosystem functioning, there may be valid precautionary reasons for caring for bearers that have solely instrumental value. 


\section{Instrumental Values Relative to Relational Values}

Is there still a need for instrumental values and the distinction between instrumental and intrinsic values? In recent years, several proposals have attempted to justify "relational values" as a way of going beyond, or at the very least supplementing, the distinction between instrumental and intrinsic values (Chan et al. 2016; Tadaki et al. 2017). The discussion has also influenced policy-advising bodies such as the IPBES framework (Pascual et al. 2017). Relational values are described as "not [being] present in things but derivative of relationships and responsibilities to them" (Chan et al. 2016). Relational values are justified by a fear that the distinction between instrumental and intrinsic values "may fail to resonate with views on personal and collective well-being, or 'what is right,' with regard to nature and the environment" and that "the usual framings of instrumental and intrinsic values fail to resonate with many lay-people and decision-makers" (Chan et al. 2016).

However, assuming that the distinction "may fail to resonate with many laypeople and decision-makers" would suggest that relational values could replace the distinction. We are offered few empirical reasons to support such a claim. However, it seems as if the distinction still plays a role, even in, for example, the IPBES framework (Pascual et al. 2017). Furthermore, it is suggested that the "debate over protecting nature for humans' sake (instrumental values) or for nature's (intrinsic value)" is a cornerstone of environmental policy (Chan et al. 2016). This would suggest the opposite of the distinction being obsolete or redundant.

However, one thing that is problematic with relational values is that they are not really anything new, and furthermore it can be accommodated in the instrumental and intrinsic value distinction. Many things that we cherish and find valuable, such as friendship or love, are difficult to make sense of based on the distinction between instrumental and intrinsic. The special obligations stemming from friendship or love is contingent upon relations rather than the properties of an object. Similarly, a part of nature "may be greatly important for an individual, the population of a certain geographical area, or a whole generation, and have no or very little importance for others living at different places and times" (Birnbacher 2004: 193). However, this makes the value extrinsic, which the above framework can accommodate. The fact that relational values are not contingent upon the properties that objects have but rather on relations does not omit the usefulness of the distinction, as value is sought "in their [that is, the components of a relational value] contribution to these intrinsically valuable relations, either as causes and causal factors (instrumental value) or as intentional objects (inherent value)" (Birnbacher 2004: 193).

Moreover, instrumental values (as well as intrinsic values) can accommodate subjective relations (Sandler 2012b: 19). Someone may prefer one knife to another because it looks nicer or due to some special attachment rather than it being better than another knife for cutting (von Wright 1963). Similarly, someone may acknowledge that driving a car to work is an efficient way of getting there but abhor cars, thus lowering the subjective instrumental value of driving a car to work (Sandler 2012b: 19). However, whereas the judgment that a knife cuts better or worse than another knife (or that driving a car is an efficient way of getting to work) may be true or false, the subjective components cannot be true or false (von Wright 1963). 
This raises the issue of what role relational values are to have when priorities are called for and what weight we should ascribe to such values. In some instances, relational values are incredibly important, as illustrated by "one thought too many" scenarios (Williams 1981). Imagine that a man can save only one of two persons who are in equal peril. One of the two is the man's wife, whereas the other is a stranger. What justification is there for the rescuer's choice? From an impartial utilitarian framework it may be the best choice to save the stranger, assuming that this will lead to greater aggregated value. But one may justify saving the wife along the lines of it being his wife, and in situations of this kind is it permissible to give precedence to one's wife relative a stranger (Williams 1981: 18). However, that would be one thought too many (Williams 1981). The motivating thought would be that it was his wife and not saving her would be unthinkable. The extra justification is one thought too many and shows the difficulty in taking an impartial view.

In other cases, however, justification based on contingent relations may be more problematic. Factors such as prejudices and norms influence the value we ascribe to objects and persons. But, such factors may have a negative impact on our judgments. After all, relational values are not necessarily consistent with environmentally friendly values; they could be hostile or indifferent. One could then make a second-order judgment regarding the justification of such judgments. However, forming such second-order judgments would require a robust ground, preferably a one that does not make second-order judgments contingent upon relations such as possibly prejudicial norms. In fact, relational values fit uneasily in relation to the discussion on keystone species. A species may be a keystone species, which is understood as being, objectively, a necessary cause for the persistence of a system, and thus have instrumental value. However, its relational value is contingent upon other factors, such as preferences or cultural values, which may be indifferent or hostile to the keystone species.

Meanwhile, an umbrella species may be deemed morally relevant due to relational values (such as cultural meaning, historical background, and so forth). However, even if relational values can accommodate umbrella species, this says nothing about species that humans do not value or are indifferent to. Thus, this is a very narrow anthropocentrism (Attfield 2015: 147) that omits both the objective instrumental and intrinsic values of other species and habitats from deliberations or decisions. Both instrumental and intrinsic values come in subjective and objective varieties (Sandler 2012b), but relational values capture only the subjective notions, where value is contingent upon a specific relation. Relational values omits robust second-order judgments regarding reasonability if not supplemented with accounts of instrumental and intrinsic values and reasons that enable second-order judgments.

\section{Summary}

This paper has discussed the notion of instrumental value. Instrumental values are often disregarded in moral philosophy or perceived as the more pedestrian cousin of intrinsic value. Instrumental value is derived from that which has intrinsic value, joined through a causal relation. By discussing different forms of causes, we may 
understand how to value and respect bearers of instrumental value. This has been exemplified by discussing environmental ethics.

However, this is merely one aspect of understanding the central ethical role of means in practice. Applied philosophy must address the relation between that which has intrinsic value and the means by which it can be attained. Such a relation is related to feasibility and the practical conditions under which we act. It also has a modest possibility of providing a component of ethics in practice, as different actions are justified in terms of whether there are different causes.

Given that specific conditions obtain, such as a means being a necessary condition for achieving an intrinsic value or final end, or that there are very few means available to reach that which has intrinsic value or is a final end, we may reach the judgment that even if something is primarily, or solely, of instrumental value, we may still be required to pay respect to that entity, organism, or act, as suggested in the discussion above on environmental policy. However, it should be remembered that not all means have instrumental value. Some are simply instrumental. Yet, some means reflect intrinsic or final value, to the extent that they are necessary causes.

Open Access This article is distributed under the terms of the Creative Commons Attribution 4.0 International License (http://creativecommons.org/licenses/by/4.0/), which permits unrestricted use, distribution, and reproduction in any medium, provided you give appropriate credit to the original author(s) and the source, provide a link to the Creative Commons license, and indicate if changes were made.

\section{References}

Attfield, R. (2015). The ethics of the global environment. Edinburgh: Edinburgh University Press.

Beckerman, W. (1994). Sustainable development: Is it a useful concept? Environmental Values, 3, 191-209.

Birnbacher, D. (2004). Limits to substitutability in nature conservation. In M. Oksanen \& J. Pietarinen (Eds.), Philosophy and biodiversity (pp. 180-198). Cambridge: Cambridge University Press.

Chan, K. M. A., et al. (2016). Opinion: Why protect nature? PNAS, 113(6), 1462-1465.

Ehrlich, P., \& Ehrlich, A. (1981). Extinction: The causes and consequences of the disappearance of species. New York: Random House.

Falcon, A. (2015). Aristotle on causality. In E. N. Zalta (Ed.), The Stanford encyclopedia of philosophy (Spring 2015 Edition), https://plato.stanford.edu/archives/spr2015/entries/aristotle-causality/

IPBES. (2018). Summary for policymakers of the regional assessment report on biodiversity and ecosystem services for Europe and Central Asia. Bonn, Germany: IPBES Secretariat.

Kagan, S. (1998). Rethinking intrinsic value. Journal of Ethics, 2, 277-297.

Kant, I. (1998). Groundwork on the metaphysics of morals. Cambridge: Cambridge University Press.

Katz, E. (1985). Organism, community, and the substitution problem. Environmental Ethics, 7, $241-256$.

Korsgaard, C. (1983). Two distinctions in goodness. The Philosophical Review, 92, 169-195.

Mackie, J. L. (1965). Causes and conditions. American Philosophical Quarterly, 2, 245-264.

Maclaurin, J., \& Sterelny, K. (2008). What is biodiversity? Chicago: Chicago University Press.

Moore, G. E. (2004). Principia ethica. Mineola, NY: Dover Philosophical Classics.

Noss, R. F. (1990). Indicators for monitoring biodiversity: A hierarchical approach. Conservation Biology, 4(4), 355-364.

Nozick, R. (1989). The examined life: Philosophical meditations. New York: Simon \& Schuster Paperbacks.

O'Neill, J. (1992). The varieties of intrinsic value. The Monist, 75, 119-137.

Pascual, U., et al. (2017). Valuing nature's contribution to people: The IPBES approach. Current Opinion in Environmental Sustainability, 26-27, 7-16. 
Peterson, M., \& Sandin, P. (2013). The last man argument revisited. Journal of Value Inquiry, 47, $121-133$

Rabinowicz, W., \& Rønnow-Rasmussen, T. (2000). A distinction in value: Intrinsic and for its own sake. Proceedings of the Aristotelian Society 100, Part 1, 33-51.

Rønnow-Rasmussen, T. (2002). Instrumental values: Strong and weak. Ethical Theory and Moral Practice, 5, 23-43.

Ross, W. D. (2002). The right and the good. Oxford: Oxford University Press.

Sandler, R. L. (2012a). Intrinsic value, ecology, and conservation. Nature Education Knowledge, 3, 4.

Sandler, R. L. (2012b). The ethics of species: An introduction. Cambridge: Cambridge University Press.

Sarkar, S. (2005). Biodiversity and environmental philosophy. Cambridge: Cambridge University Press.

Tadaki, M., Sinner, J., \& Chan, K. M. A. (2017). Making sense of environmental value: A typology of concepts. Ecology and Society. https://doi.org/10.5751/ES-08999-220107.

von Wright, G. H. (1963). The varieties of goodness. London: Routledge, https://www.giffordlectures .org/books/varieties-goodness/ii-instrumental-and-technical-goodness

Williams, B. (1981). Persons, character, and morality. In Moral Luck (pp. 1-19). Cambridge: Cambridge University Press.

Woods, M. (2017). Rethinking wilderness. Peterborough, ON: Broadview Press.

Zimmerman, M. J. (2001). The nature of intrinsic value. Oxford: Rowman \& Littlefield Inc.

Publisher's Note Springer Nature remains neutral with regard to jurisdictional claims in published maps and institutional affiliations. 